\title{
Effect of processing parameters on in situ screen printing-assisted synthesis and electrical properties of $\mathrm{Ti}_{3} \mathrm{SiC}_{2}$-based structures
}

\author{
Mylena LORENZ ${ }^{a}$, Nahum TRAVITZKY ${ }^{a, b}$, Carlos R. RAMBO ${ }^{c, *}$ \\ ${ }^{a}$ Department of Materials Science, University of Erlangen-Nuremberg, 91058 Erlangen, Germany \\ ${ }^{b}$ Tomsk Polytechnic University, 634050 Tomsk, Russia \\ ${ }^{c}$ Department of Electrical and Electronic Engineering, Federal University of Santa Catarina, \\ 88040-900 Florianopolis, Brazil
}

Received: July 12, 2020; Revised: September 17, 2020; Accepted: September 26, 2020

(C) The Author(s) 2020.

\begin{abstract}
This work reports on the development of pastes containing $\mathrm{Ti}, \mathrm{TiC}, \mathrm{Si}$, and $\mathrm{C}$ elementary powders for in situ synthesis of $\mathrm{Ti}_{3} \mathrm{SiC}_{2}$ via screen printing. Four paste compositions were manufactured using two powder mixtures $(\mathrm{Ti} / \mathrm{Si} / \mathrm{C}$ and $\mathrm{Ti} / \mathrm{TiC} / \mathrm{Si} / \mathrm{C})$ with different stoichiometry. The pastes were screen printed onto $\mathrm{Al}_{2} \mathrm{O}_{3}$ substrates and sintered at $1400{ }^{\circ} \mathrm{C}$ in argon varying the dwell time from 1 to $5 \mathrm{~h}$. The printed pastes containing $\mathrm{TiC}$ and excess of $\mathrm{Si}$ exhibited the lowest surface roughness and after $5 \mathrm{~h}$ sintering comprised of $\mathrm{Ti}_{3} \mathrm{SiC}_{2}$ as the majority phase. The electrical conductivity of this sample was found to range from $4.63 \times 10^{4}$ to $2.57 \times 10^{5} \mathrm{~S} \cdot \mathrm{m}^{-1}$ in a temperature range of $25-400{ }^{\circ} \mathrm{C}$.
\end{abstract}

Keywords: MAX phases; $\mathrm{Ti}_{3} \mathrm{SiC}_{2}$; screen printing; in situ synthesis; electrical conductivity

\section{Introduction}

Titanium silicon carbide $\left(\mathrm{Ti}_{3} \mathrm{SiC}_{2}\right)$ is a versatile and remarkable ceramic, which over the past years has been gaining attention. It provides the high eletrical and thermal conductivity caracteristics of metals and the mechanical and chemical stability over a wide range of temperature characteristics of ceramics, making it a material with pronounced potential for a wide field of application including eletrical and electronics [1]. Additionally, $\mathrm{Ti}_{3} \mathrm{SiC}_{2}$ is well-known for its unique combination of mechanical, electrical, and thermal properties of both metal and ceramic materials. It exhibits high electrical and thermal conductivity,

* Corresponding author.

E-mail: carlos.rambo@ufsc.br excellent thermal shock resistance, oxidation resistance, thermal and chemical resistance, easy machinability, high rigidity, high hardness, and high elastic modulus [2]. The reported electrical conductivity of this material ranges from $4.5 \times 10^{6}$ to $9.6 \times 10^{6} \Omega^{-1} \cdot \mathrm{m}^{-1}$, which is considerably high for ceramics, and makes it a potential candidate for applications as electrical contacts, in high-power electronics, corrosion protective coatings, and heat exchangers [3,4]. Different technologies have been used for the synthesis and processing of bulk and $\mathrm{Ti}_{3} \mathrm{SiC}_{2}$ films, such as temperature fluctuation synthesis [5,6], reactive HIP [7], spark plasma sintering [8], ink-jet printing [9], preceramic paper fabrication [10], DC magnetron sputtering [11], 3D-printing [12], and mechanical alloying [13]. Additionally, Dcosta et al. [14] fabricated $\mathrm{Ti}_{3} \mathrm{SiC}_{2}$ powder-based structures through $3 \mathrm{D}$ printing combined with cold isostatic pressurizing and sintering. 
In electronics, ink-jet printing and screen printing have gained attention due to their low cost, speed velocity, and simplicity. Screen printing is one of the printing techniques currently used for the fabrication of conductive lines and films. This technique is gradually replacing the conventional methods for production of small and medium scale-integrated electronic devices. It is a cost-effective high-performance and highprocessing-speed technique, which is environmentally friendly, has high reliability, and allows the use of different printing substrates [15]. Phair et al. [16] reported that the composition and rheological properties of the required paste and the screen printing parameters are directly related to the performance of this process and the quality of the screen printed ceramic films. The screen printing process itself consists in the deposition of a ceramic paste through a screen mesh and under a determined pressure applied by a squeegee allowing the fabrication of thick films. The printing geometry is drawn onto the screen mesh and thus, it uses only the sufficient quantity of the pastes thereby reducing waste [17]. This process has been used successfully for the fabrication of several electronic devices. Faddoul et al. [15] reported the screen printing of silver pastes on low temperature co-fired ceramic (LTCC) substrates for microelectronic applications. Goldberg et al. [18] showed that screen printing can be applied for batch fabrication of integrated chemical-sensor arrays. Phair [19] reported the screen printing of oxide layers in solid oxide fuel cells (SOFC). The processing of $\mathrm{Ti}_{3} \mathrm{SiC}_{2}$-based pastes via screen printing has been already investigated by Carrijo et al. [20]. However, as of yet there is no report on in situ synthesis of $\mathrm{Ti}_{3} \mathrm{SiC}_{2}$ from its elemental powder via screen printing, in which the main advantage is to save processing steps.
Additionally, the use of alumina as substrate enables the preparation of $\mathrm{Ti}_{3} \mathrm{SiC}_{2}-\mathrm{Al}_{2} \mathrm{O}_{3}$ layered composites for applications that require high temperatures due to their comparable thermal expansion coefficients [21].

In this work, we propose the production of pastes containing commercial $\mathrm{Ti}, \mathrm{TiC}, \mathrm{SiC}$, and graphite powders to synthesize $\mathrm{Ti}_{3} \mathrm{SiC}_{2}$ thick films via screen printing onto paper derived $\mathrm{Al}_{2} \mathrm{O}_{3}$ substrates. The rheological properties of the pastes produced for screen printing, as well as the microstructure and electrical properties of the printed structures were also investigated.

\section{Experimental}

For the production of pastes, Ti $(25 \mu \mathrm{m}, \mathrm{ABCR} \mathrm{GmbH}$ \& Co. KG, Karslruhe, Germany), TiC (2.5 $\mu \mathrm{m}$, H.C.Starck, Laufenberg, Germany), Si (3 $\mu \mathrm{m}$, Siligrain, Kristiansand, Norway), and graphite ( $4 \mu \mathrm{m}$, Lehmann und Voss Co. KG, Hamburg, Germany) powders were used.

For the synthesis of $\mathrm{Ti}_{3} \mathrm{SiC}_{2}$, two different powder mixtures were used: (1) $\mathrm{Ti} / \mathrm{Si} / \mathrm{C}$ and (2) $\mathrm{Ti} / \mathrm{TiC} / \mathrm{Si} / \mathrm{C}$. For each mixture, two different stoichiometries were prepared (Table 1). Ethyl cellulose (EC) and terpineol (Fluka Chemie $\mathrm{GmbH}$, Switzerland) were used as binder and solvent, respectively. The amount of carbon provided from binder and solvent was also taken into account. The binder was first dissolved in terpineol using mechanical stirring at $80{ }^{\circ} \mathrm{C}$ and subsequently elementary powders were added using a three-roll mill (Exakt Advanced Technologies GmbH, Germany).

The numbers in the nomenclature of the samples specify the composition and stoichiometry of the pastes. The first number corresponds to the composition (mixture type) and the second is related to the amount

Table 1 Composition of pastes

\begin{tabular}{|c|c|c|c|c|c|c|c|c|}
\hline & \multicolumn{2}{|c|}{ P1.1 } & \multicolumn{2}{|c|}{$\mathrm{P} 1.2$} & \multicolumn{2}{|c|}{ P2.1 } & \multicolumn{2}{|c|}{$\mathrm{P} 2.2$} \\
\hline & $\left(\mathrm{vol}^{\%} \%\right)$ & $(w t \%)$ & $\left(\mathrm{vol}_{\%} \%\right)$ & $(w t \%)$ & $\left(\mathrm{vol}^{2} \%\right)$ & $(w t \%)$ & $(\mathrm{vol} \%)$ & $(w t \%)$ \\
\hline Terpineol & 65.5 & 41.6 & 67.3 & 42.1 & 61.1 & 33.1 & 61.6 & 34.5 \\
\hline $\mathrm{EC}$ & 7.2 & 19.8 & 4.5 & 12.1 & 3.4 & 7.8 & 2.9 & 7.0 \\
\hline $\mathrm{Ti}$ & 10.5 & 26.2 & 13.0 & 32.0 & 9.6 & 20.6 & 8.4 & 18.5 \\
\hline $\mathrm{Si}$ & 7.9 & 10.2 & 9.7 & 12.5 & 10.8 & 12.0 & 14.1 & 16.1 \\
\hline Graphite & 8.9 & 2.2 & 5.5 & 1.3 & 4.1 & 0.9 & 3.5 & 0.8 \\
\hline $\mathrm{TiC}$ & - & - & - & - & 11.0 & 25.7 & 9.5 & 23.1 \\
\hline Stoich. & \multicolumn{2}{|c|}{$3 \mathrm{Ti} / 2 \mathrm{Si} / 2 \mathrm{C}$} & \multicolumn{2}{|c|}{$3 \mathrm{Ti} / 2 \mathrm{Si} / \mathrm{C}$} & \multicolumn{2}{|c|}{$3 \mathrm{Ti} / 3 \mathrm{TiC} / 3 \mathrm{Si} / \mathrm{C}$} & \multicolumn{2}{|c|}{$3 \mathrm{Ti} / 3 \mathrm{TiC} / 4.5 \mathrm{Si} / \mathrm{C}$} \\
\hline Mixture & \multicolumn{4}{|c|}{$\mathrm{Ti} / \mathrm{Si} / \mathrm{C}$} & \multicolumn{4}{|c|}{$\mathrm{Ti} / \mathrm{TiC} / \mathrm{Si} / \mathrm{C}$} \\
\hline
\end{tabular}


of precursors. For example, P1.1 corresponds to the paste produced with $\mathrm{Ti}, \mathrm{Si}$, and $\mathrm{C}$ powders with $3 \mathrm{Ti} /$ $2 \mathrm{Si} / 2 \mathrm{C}$ powder composition, whereas $\mathrm{P} 2.2$ corresponds to the paste produced with $\mathrm{Ti}, \mathrm{TiC}, \mathrm{Si}, \mathrm{C}$ powders but with stoichiometry of $3 \mathrm{Ti} / 3 \mathrm{TiC} / 4.5 / \mathrm{Si} / \mathrm{C}$.

For the printing process, a screen printer (ELA, DEK - ASM Assembly Systems GmbH, Germany) was used. The pastes containing the elemental powders were deposited onto paper-derived $\mathrm{Al}_{2} \mathrm{O}_{3}$ substrates. The preparation of printing substrates was previously reported in Ref. [22]. The screen used was made of polyester (Koenen $\mathrm{GmbH}$, Germany) with a Mesh opening of $333 \mu \mathrm{m}$, an open screen surface of $49 \%$, and a Mesh count of $21 \mathrm{~cm}^{-1}$. The printing process was carried out with a squeegee pressure of $100 \mathrm{~N}$ and a print speed of $150 \mathrm{~mm} / \mathrm{s}$. The one-layer printed structures were left drying for $24 \mathrm{~h}$ at room temperature $\left(\sim 20{ }^{\circ} \mathrm{C}\right)$ and then dried for $24 \mathrm{~h}$ at $80{ }^{\circ} \mathrm{C}$. Afterwards, the green screen printed samples were sintered at $1400{ }^{\circ} \mathrm{C}$ for 1 , 3 , and $5 \mathrm{~h}$ in a flowing argon atmosphere with heating and cooling rates of $180 \mathrm{~K} / \mathrm{h}$.

The print design is shown in Fig. 1(a). It was divided in two parts: (1) corresponding to the thinner line and superior part of the design and (2) to the larger and lower part. This classification was made in order to obtain more accurate measurements for the characterization of the printed structures. Figure 1(b) shows a representative photograph of a screen-printed sample with the $\mathrm{P} 2.2$ formulation.

Before $\mathrm{Ti}_{3} \mathrm{SiC}_{2}$ synthesis, investigation of the rheological behavior of the pastes was carried out at 20 ${ }^{\circ} \mathrm{C}$ using a modular compact rheometer (MCR 302, Anton Paar GmbH, Germany). For high viscosity samples the parallel-plate geometry with diameter of $50 \mathrm{~mm}$ and gap of $1 \mathrm{~mm}$ was required. For low viscosity samples a cone and plate set up with diameter

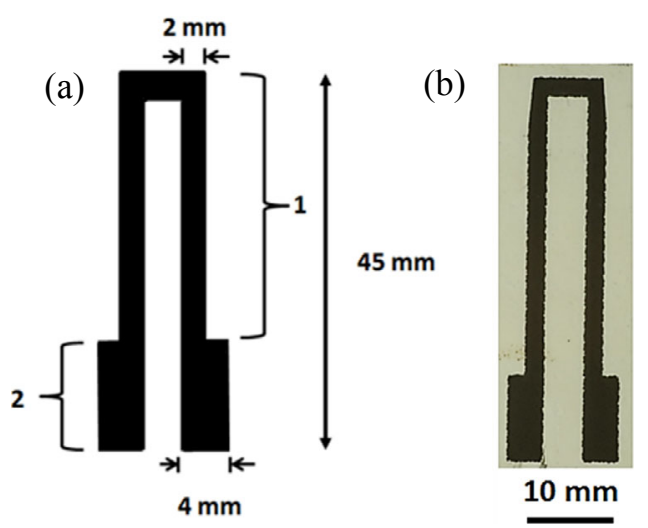

Fig. 1 (a) Printing design and (b) screen-printed P2.2 sample. of $17 \mathrm{~mm}$ and gap of $1 \mathrm{~mm}$ was used. The flow behavior measurements were performed with shear rates ranging from 1 to $100 \mathrm{~s}^{-1}$. Measurements at higher shear rates were not performed once all pastes presented a shear thinning behavior. Storage modulus $\left(G^{\prime}\right)$ and loss modulus $\left(G^{\prime \prime}\right)$ were measured using a sweep measurement at a frequency of $1.0 \mathrm{~Hz}$ and shear stresses ranging from 0.01 to $1000 \mathrm{~Pa}$. The 3-step recovery analysis was used to simulate the behavior of the pastes during screen printing. In the first and third steps, an oscillatory shear stress of $1 \mathrm{~Pa}$ at $1.0 \mathrm{~Hz}$ was applied for $600 \mathrm{~s}$. In the second step during $180 \mathrm{~s}$ a high rotational shear rate of $100 \mathrm{~s}^{-1}$ was applied. The recovery ratio (\%) was calculated from the measurement on the first and third steps using Eq. (1) [23]:

$$
\text { Recovery ratio }=\frac{G^{\prime} \text { at } 1680 \mathrm{~s} \text { in third step }}{G^{\prime} \text { at } 900 \mathrm{~s} \text { in the first step }} \times 100
$$

After screen printing, the surface properties of the green and sintered screen printed layers in order were evaluated by confocal microscopy (NanoFocus AG, Oberhausen, Germany). For the line profile, topography images and measurement of thickness and roughness values (a scan image surface $\approx 1.0 \mathrm{~mm} \times 3.0 \mathrm{~mm}$ ) of part 1 of the print design (Fig. 1(a)) was used. For data calculation the WinSam 2.6.08 software (Department of Manufacturing Technology - LFT, University of Erlangen-Nuremberg) was used. The software enables a three-dimensional surface area scan of the sample. The quality of the images was optimized using a leveling method called line to line. The line-to-line leveling method comprises the adjustment of an image profile line with a polynomial equation, which is then subtracted from that image line. The average height of each line is set equal to the previous corrected line as proposed by Méndez-Vilas and Diaz [24]. The calculation of surface roughness parameters such as average surface roughness $\left(R_{\mathrm{a}}\right)$ and root mean square deviation $\left(R_{\mathrm{q}}\right)$ was performed by drawing ten section lines of $\sim 2$ $\mathrm{mm}$ over each screen-printed layer. For the calculation along a measured line $(Z(x))$, Eqs. (2) and (3) were needed [25]:

$$
\begin{aligned}
& R_{\mathrm{a}}=\frac{1}{l} \int_{0}^{l}|Z(x)| \mathrm{d} x \\
& R_{\mathrm{q}}=\sqrt{\frac{1}{l} \int_{0}^{l} Z^{2}(x) \mathrm{d} x}
\end{aligned}
$$

Solid area films of all paste compositions were prepared manually and sintered with the same sintering 
profile as the screen-printed samples and used for X-ray diffraction analysis (D8 Advance, Bruker Corporation, USA). The solid area films were prepared in order to avoid interference from the substrates during analysis. The samples were exposed to monochromatic $\mathrm{Cu} \mathrm{K} \alpha$ radiation with a scanning rate of $0.01\left(^{\circ}\right) / \mathrm{s}$ over $2 \theta$ between $25^{\circ}$ and $95^{\circ}$. The microstructure of the sintered samples was evaluated using scanning electron microscopy (SEM, Quanta 200, FEI, Czech Republic) coupled with energy-dispersive $\mathrm{X}$-ray spectroscopy (EDX, INCA $\mathrm{x}$-sight TVA3, Oxford Instruments, UK) for compositional analysis.

Part 2 of the print design (Fig. 1(a)) was used for electrical measurements of the sintered screen printed layers. A heating apparatus (PE95/T95 System Controller, Linkam Scientific Instrument, UK) was used for the measurements at temperatures ranging between 25 and $400{ }^{\circ} \mathrm{C}$. The electrical resistivity was evaluated using a DC four-point probe method (Keithley 2450 source Metter, Tektronix Inc., USA) and the values were obtained through Eqs. (4) and (5):

$$
\begin{gathered}
\rho_{\mathrm{m}}=2 \pi s R \\
\rho=0.73\left\lfloor\frac{t h}{s}\right\rfloor \rho_{\mathrm{m}}
\end{gathered}
$$

where $\rho_{\mathrm{m}}=$ measured resistivity $(\Omega \cdot \mathrm{m}) ; \rho=$ resistivity $(\Omega \cdot \mathrm{m}) ; R=$ resistance $(\Omega) ;$ th $=$ thickness $(\mathrm{m}) ; s=$ probe distance $(\mathrm{m})$.

A correction factor $(0.73)$ is required when a conductive film is deposited onto an insulating surface, once the ratio between sample thickness and distance of probes $(t h / s)$ is smaller than 1. The samples' thicknesses were measured using a confocal microscope and all samples were analyzed in triplicate.

\section{Results and discussion}

Figure 2 shows the flow data (Fig. 2(a)) and viscoelastic properties (Fig. 2(b)) of the pastes.

All compositions presented a shear thinning behavior. The highest viscosity value was found for P1.1 despite having the lowest solid content among all pastes. This suggests that the EC content is the main factor influencing paste viscosity. For all compositions, the values of $G^{\prime \prime}$ were higher than $G^{\prime}$ suggesting liquidlike behavior (Fig. 2(b)). These values increased with the increase in the viscosity. All samples present a LVER (linear viscoelastic region) and absence of cross

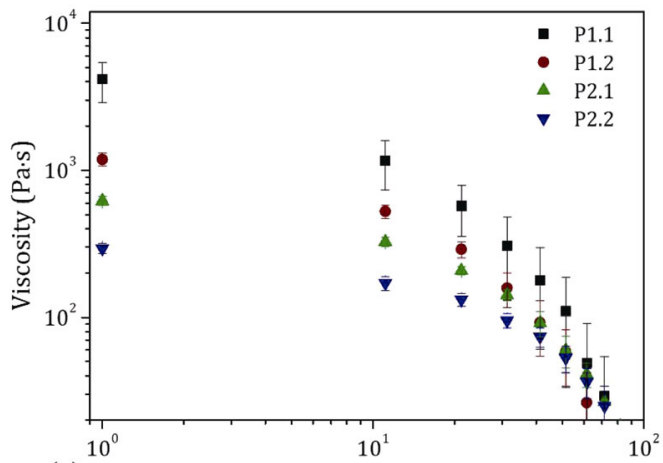

(a)

Shear rate $\left(\mathrm{s}^{-1}\right)$

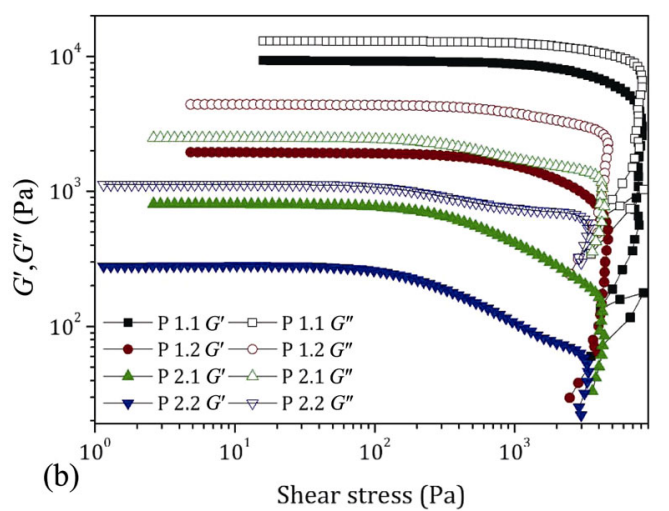

Fig. 2 (a) Viscosity vs. shear rate curves and (b) storage $\left(G^{\prime}\right)$ and loss $\left(G^{\prime \prime}\right)$ modulus in function of the shear stress for the different paste compositions.

over point prior to a shear stress of $100 \mathrm{~Pa}$.

The 3-step recovery analysis (Fig. 3) revealed a time-dependent viscosity in all samples. This behavior was probable due to the high particle content, which leads to a progressive breakdown of the network during shearing as also observed by Inukai et al. [23].

The main influence can be attributed to the EC content of the pastes. P2.1 and P2.2 exhibited the lowest recovery ratios of $25 \pm 8.9 \%$ and $26 \pm 8.9 \%$, respectively, and also the lowest viscosity values. The opposite was observed for P1.1 and P1.2, which presented the highest recovery ratios $(68 \pm 1.6 \%$ and $96 \pm 4.7 \%$, respectively) and the highest viscosities. Phair et al. [16] observed the same behavior for screen printed zirconia films. In their study, the content of ethyl cellulose in the pastes directly influenced the recovery ratio of the pastes, which increased with increasing EC content.

Figure 4 shows the topography images of the green screen printed parts and the sintered P2.1 and P2.2 samples at $1400{ }^{\circ} \mathrm{C}$ for $5 \mathrm{~h}$ in argon.

Table 2 shows the $R_{\mathrm{a}}$ and $R_{\mathrm{q}}$ values of the green and sintered samples, where the influence of the powder 

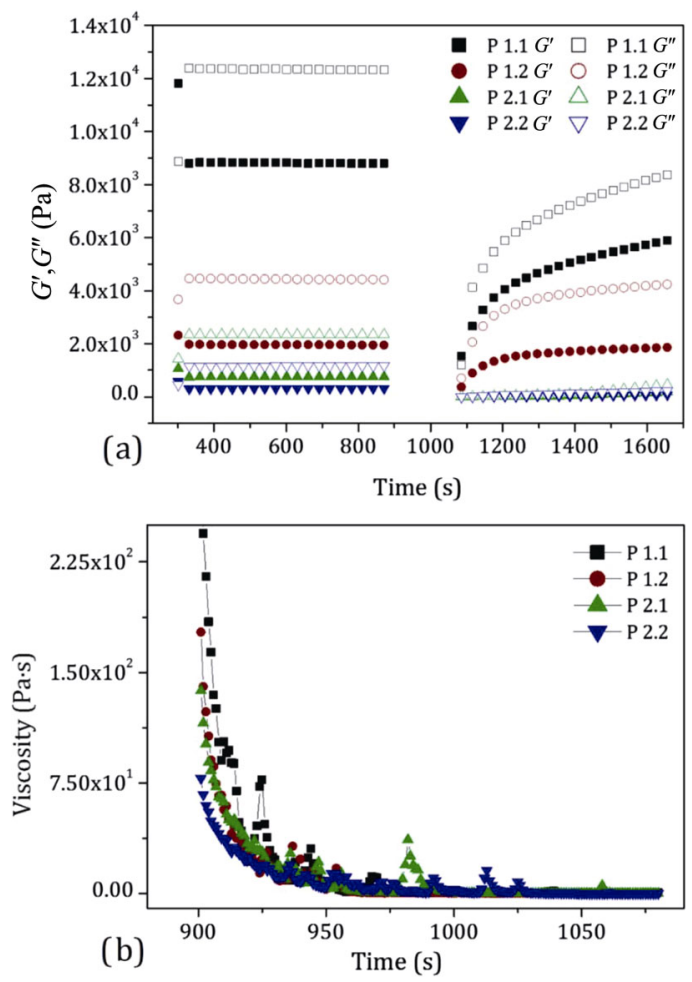

Fig. 3 3-step recovery measurement. Storage $\left(G^{\prime}\right)$ modulus and viscosity as a function of elapsed time for all paste compositions.
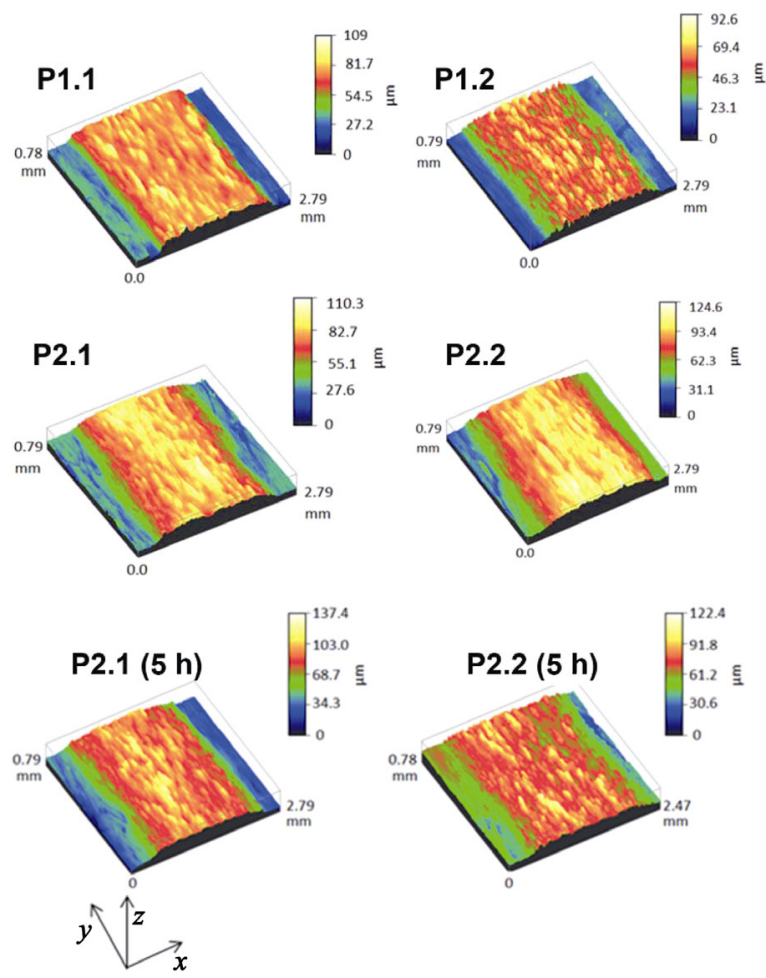

Fig. 4 Topography of green screen printed layers of all paste compositions and pastes $\mathrm{P} 2.1$ and $\mathrm{P} 2.2$ after $5 \mathrm{~h}$ sintering at $1400{ }^{\circ} \mathrm{C}$ in argon.

Table $2 R_{\mathrm{a}}$ and $\boldsymbol{R}_{\mathrm{q}}$ values of the green and sintered screen-printed layers during different time at $1400{ }^{\circ} \mathrm{C}$

\begin{tabular}{ccccc}
\hline & \multirow{2}{*}{ Green } & \multicolumn{3}{c}{ Sintering time } \\
\cline { 3 - 5 } Paste & & $1 \mathrm{~h}$ & $3 \mathrm{~h}$ & $5 \mathrm{~h}$ \\
\cline { 2 - 5 } & $R_{\mathrm{a}}(\mu \mathrm{m}) / R_{\mathrm{q}}(\mu \mathrm{m})$ & $R_{\mathrm{a}}(\mu \mathrm{m}) / R_{\mathrm{q}}(\mu \mathrm{m})$ & $R_{\mathrm{a}}(\mu \mathrm{m}) / R_{\mathrm{q}}(\mu \mathrm{m})$ & $R_{\mathrm{a}}(\mu \mathrm{m}) / R_{\mathrm{q}}(\mu \mathrm{m})$ \\
\hline P1.1 & $5.7 \pm 1.1 / 6.9 \pm 1.1$ & $9.7 \pm 1.1 / 12.9 \pm 1.1$ & $9.5 \pm 2.7 / 13.2 \pm 0.6$ & $13.0 \pm 1.8 / 16.4 \pm 2.7$ \\
P1.2 & $5.7 \pm 0.6 / 7.2 \pm 0.7$ & $9.8 \pm 0.9 / 11.9 \pm 1.1$ & $10.7 \pm 1.3 / 13.4 \pm 1.4$ & $11.8 \pm 1.6 / 15.3 \pm 3.0$ \\
P2.1 & $6.5 \pm 0.5 / 8.0 \pm 0.7$ & $5.2 \pm 0.4 / 6.5 \pm 0.5$ & $5.1 \pm 0.8 / 6.4 \pm 1.0$ & $6.1 \pm 1.0 / 7.7 \pm 1.1$ \\
P2.2 & $4.7 \pm 0.7 / 6.0 \pm 0.9$ & $5.7 \pm 0.6 / 7.2 \pm 0.8$ & $5.0 \pm 0.6 / 6.2 \pm 0.8$ & $6.3 \pm 0.5 / 8.1 \pm 0.8$ \\
\hline
\end{tabular}

composition on the roughness can be observed. After sintering, films formed from pastes P2.1 and P2.2 exhibited lower $R_{\mathrm{a}}$ and $R_{\mathrm{q}}$ values and were smoother than the films formed from pastes P1.1 and P1.2 regardless of the sintering time. $\mathrm{P} 1.1$ and $\mathrm{P} 1.2$ have the highest EC content, which resulted in higher height variation on sample's surface after sintering due to decomposition of EC and hence formation of defects, as already reported in Refs. [26,27]. The mass loss on the surface of the screen-printed films after sintering can be noticed as alterations in the topography images. However, the influence of the powder composition on the surface roughness is evident after sintering. The increase in thickness and surface roughness can be attributed to the reaction and products formed during sintering.

Figure 5 shows the X-ray diffraction patterns for the films formed from all pastes after different sintering time at $1400{ }^{\circ} \mathrm{C} . \mathrm{Ti}_{3} \mathrm{SiC}_{2}$ was obtained for all paste compositions in the sintering time range of $1-5 \mathrm{~h}$. However, almost all films exhibited the presence of other minority phases. Layers from pastes P1.1 and $\mathrm{P} 1.2$, which have no TiC in their initial composition, contain $\mathrm{TiSi}_{2}$ and $\mathrm{Ti}_{5} \mathrm{Si}_{3}$ as secondary phases. Layers from P2.1 and P2.2, which contained both TiC and excess $\mathrm{Si}$, exhibit $\mathrm{SiC}$ as an additional phase. Furthermore, layers formed from pastes with $\mathrm{TiC}$ in their initial composition regardless of the stoichiometry, are composed by $\mathrm{Ti}_{3} \mathrm{SiC}_{2}$ after 3 and $5 \mathrm{~h}$ sintering, precisely the layers formed from paste P2.1 after 3 and 

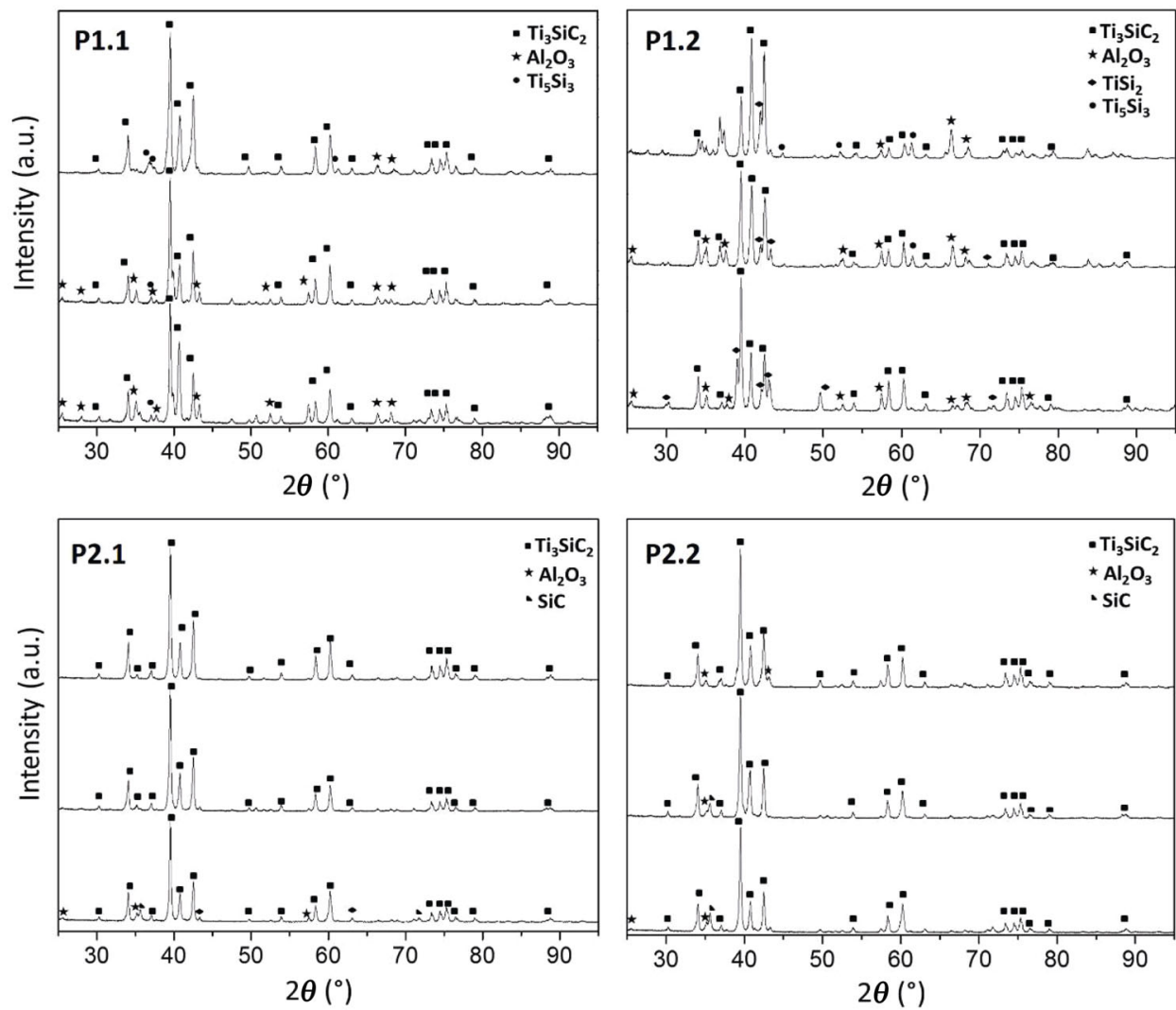

Fig. 5 X-ray diffraction patterns of films formed from all paste compositions after sintering at $1400{ }^{\circ} \mathrm{C}$ for 1,3 , and $5 \mathrm{~h}$.

$5 \mathrm{~h}$ of sintering and paste P2.2 after sintering for $5 \mathrm{~h}$, except for the presence of small peaks of $\mathrm{Al}_{2} \mathrm{O}_{3}$ in the later.

Figure 6 shows the microstructure of the layers after different sintering time. A highly porous structure is noticed from the layers formed from pastes P1.1 and $\mathrm{P} 1.2$ in comparison to those formed from pastes P2.1 and P2.2. Moreover, an increase in the density of the printed films is evident for layers formed from pastes P2.1 and P2.2 with increasing sintering time. Corroborating with XRD results, all samples exhibited $\mathrm{Ti}_{3} \mathrm{SiC}_{2}$ after sintering at different time. Although none of the samples presented a reaction zone at the interface between the substrate and the printed layers (Fig. 6, third column), samples produced from pastes $\mathrm{P} 1.1$ and $\mathrm{P} 1.2$ exhibit $\mathrm{Al}_{2} \mathrm{O}_{3}$ inclusions and samples sintered for 1 and $3 \mathrm{~h}$ contained $\mathrm{TiO}_{2}$ within their structures. Samples P1.1 and P1.2 exhibit a very porous structure, with phase discontinuity and inhomogeneous phase profile.

The EDX mapping around the interface between the $\mathrm{Al}_{2} \mathrm{O}_{3}$ substrate and the screen printed films produced from pastes $\mathrm{P} 1.1, \mathrm{P} 1.2, \mathrm{P} 2.1$, and $\mathrm{P} 2.2$ after $5 \mathrm{~h}$ sintering is shown in Fig. 7. $\mathrm{TiO}_{2}$ was not found after 5 h sintering on P2.1 and P2.2 screen printed films. The possible reason for the formation of $\mathrm{TiO}_{2}$ is the native oxide layer present on the surface of Ti particles. The films produced from pastes P2.1 and P2.2 exhibit a higher content of Si than P1.1 and P1.2. Hence, full formation of $\mathrm{Ti}_{3} \mathrm{SiC}_{2}$ is expected. Moreover, a nonhomogeneous distribution of $\mathrm{Si}$ in the P1.1 and P1.2 screen printed films can be seen, which suggests that the initial content of $\mathrm{Si}$ in the reactants was insufficient to ensure synthesis of pure $\mathrm{Ti}_{3} \mathrm{SiC}_{2}$.

Few works have reported the formation of unwanted impurity phases, such as $\mathrm{TiC}, \mathrm{Ti}_{5} \mathrm{Si}_{3}$, and $\mathrm{TiSi}_{2}$ during the synthesis of $\mathrm{Ti}_{3} \mathrm{SiC}_{2}$. Sato et al. [28] reported the formation of $\mathrm{Ti}_{5} \mathrm{Si}_{3}$ as secondary phase after synthesis of $\mathrm{Ti}_{3} \mathrm{SiC}_{2}$ from elementary powders of $\mathrm{Ti}, \mathrm{Si}$, and $\mathrm{C}$. Racault et al. [29] reported a solid-state synthesis route, which resulted in $\mathrm{Ti}_{3} \mathrm{SiC}_{2}$ with less than 5 at $\%$ of $\mathrm{TiC}$. Arunajatesan and Carim [30] proposed an arc-melting and annealing route for $\mathrm{Ti}_{3} \mathrm{SiC}_{2}$ synthesis, where the highest purity sample contained $2 \mathrm{vol} \% \mathrm{TiC}$ as second phase. Several attempts have been suggested for the synthesis of $\mathrm{Ti}_{3} \mathrm{SiC}_{2}$ using different starting compositions, such as $\mathrm{Ti} / \mathrm{Si} / \mathrm{C}$ [31], Ti/SiC/C [32], Ti/Si/TiC [33], and $\mathrm{Ti} / \mathrm{Si} / \mathrm{C} / \mathrm{SiC}$ [34]. Depending on the chosen starting 

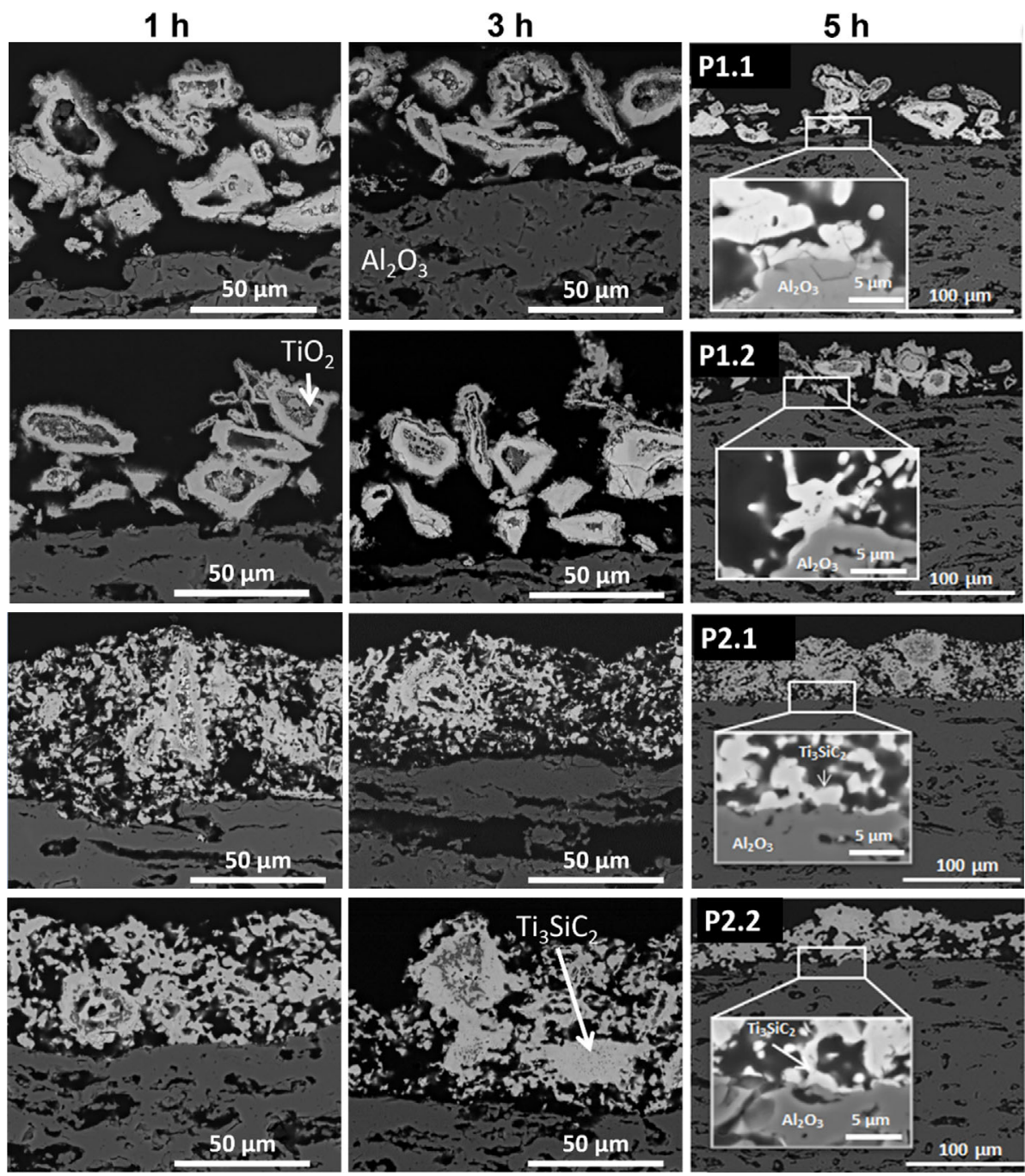

Fig. 6 SEM micrographs of the sintered screen printed layers of all paste compositions at $1400{ }^{\circ} \mathrm{C}$ in argon.

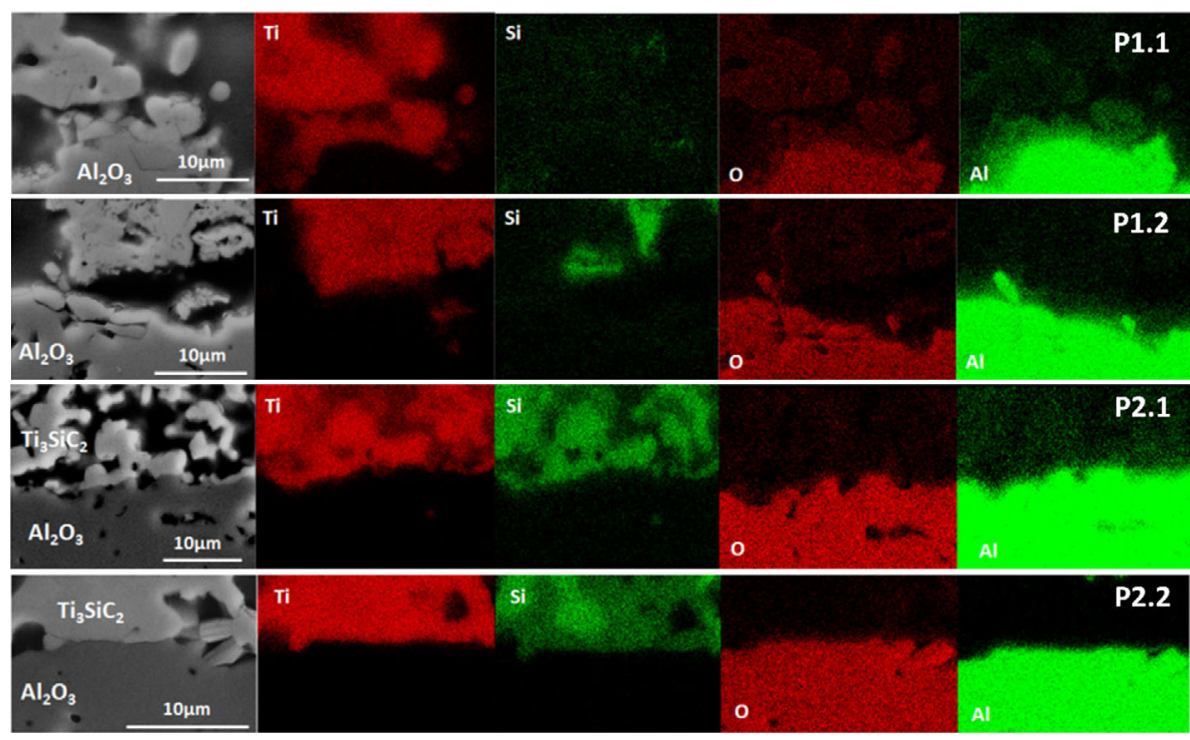

Fig. 7 EDX mapping of screen printed films after $5 \mathrm{~h}$ sintering at $1400{ }^{\circ} \mathrm{C}$ in argon. The highlighted colored regions denote for different detected elements. 
reactants, different reaction paths were obtained [35]. In studies where $\mathrm{Ti} / \mathrm{Si} / \mathrm{C}$ were used as reactant powders, it was reported that the $\mathrm{Si}$ loss was the most likely reason for the difficulty of forming a $\mathrm{Ti}_{3} \mathrm{SiC}_{2}$ single phase [36] and therefore, the thermal stability can be increased by inhibiting Si removal from the surface [4]. With excess of both $\mathrm{TiC}$ and $\mathrm{Si}$, Lorenz et al. [37] successfully synthesized paper-derived $\mathrm{Ti}_{3} \mathrm{SiC}_{2}$ by adjusting the starting stoichiometry to $3 \mathrm{Ti} / 3 \mathrm{TiC} / 3 \mathrm{Si} / \mathrm{C}$. Therefore, for this work the starting compositions $\mathrm{Ti} / \mathrm{Si} / \mathrm{C}$ and $\mathrm{Ti} / \mathrm{Si} / \mathrm{TiC} / \mathrm{C}$ were selected. Here, although the presence of $\mathrm{TiSi}_{2}$ and $\mathrm{Ti}_{5} \mathrm{Si}_{3}$ in the sintered screen-printed films formed from pastes P1.1 and P1.2 were not detected, the $\mathrm{Ti}_{3} \mathrm{SiC}_{2}$ content in layers formed from pastes P2.1 and P2.2 was noticed to be higher than those formed from P1.1 and P1.2. Furthermore, increasing the sintering time led to an increase in the $\mathrm{Ti}_{3} \mathrm{SiC}_{2}$ content formed from paste P2.2 and after $5 \mathrm{~h}$ sintering increased densification of the films formed from both P2.1 and P2.2 occurred. The increased yield and densification is attributed to the replacement of the carbon source to carbides in the starting reactants, which are known to reduce the amount of secondary phases formed. The Si loss is the most likely reason for the difficulty of forming $\mathrm{Ti}_{3} \mathrm{SiC}_{2}$ single phase, as reported by Radhakrishnan et al. [38].

As the layers produced from pastes $\mathrm{P} 2.1$ and $\mathrm{P} 2.2$ exhibited the largest amount of $\mathrm{Ti}_{3} \mathrm{SiC}_{2}$ phase of all tested pastes after $5 \mathrm{~h}$ of sintering, their electrical properties were analyzed.

Figure 8 shows the electrical conductivity as a function of temperature for the layers formed from pastes P2.1 and P2.2 after $5 \mathrm{~h}$ sintering at $1400{ }^{\circ} \mathrm{C}$.

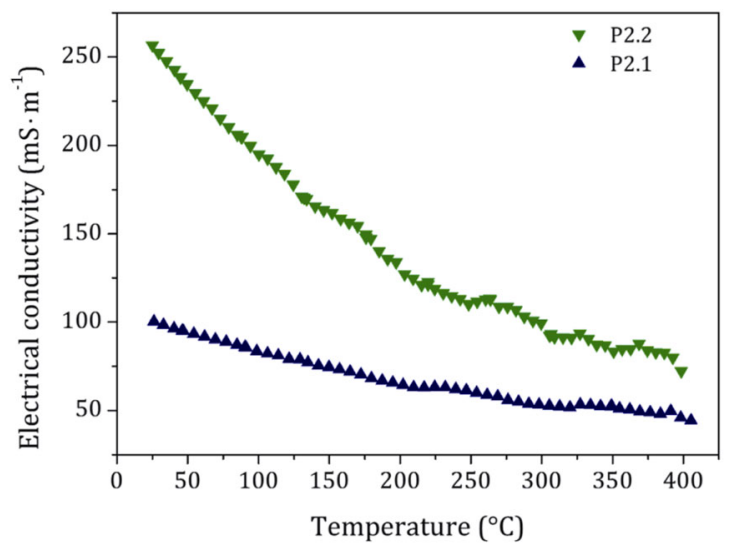

Fig. 8 Electrical conductivity vs. temperature of films formed from pastes P2.1 and P2.2 after $5 \mathrm{~h}$ sintering at $1400{ }^{\circ} \mathrm{C}$.
Both P2.1 and P2.2 structures exhibit a metallic-like behavior, where the resistivity increased with the increasing temperature. These results agree with Yoo et al. [39] who studied the electrical behavior of bulk $\mathrm{Ti}_{3} \mathrm{SiC}_{2}$ in the temperature range from 26 to $576{ }^{\circ} \mathrm{C}$. However, the electrical conductivity at 25 and $400{ }^{\circ} \mathrm{C}$ of the screen-printed layers produced from pastes P2.1 and P2.2 after $5 \mathrm{~h}$ sintering (Table 3) was two orders of magnitude lower than reported in literature. The sample P2.1 is less conductive than the sample P2.2 regardless of the presence of alumina in the later. Effective conductive paths may differ among samples with similar composition. Although statistically significant especially for lower temperatures, the difference between both samples lies within the same order of magnitude.

Palmquist et al. [40] performed a study involving the synthesis of different MAX phases in the Ti-Si-C systems by thin film fabrication via magnetron sputtering of $\mathrm{Ti}, \mathrm{Si}$, and $\mathrm{C}$ targets. They noticed that resistivity of $\mathrm{M}_{n+1} \mathrm{AX}_{n}$ phase films were noticeably low $\left(\mathrm{Ti}_{3} \mathrm{SiC}_{2}\right.$ in a range of $\left.0.5-0.3 \mu \Omega \cdot \mathrm{m}\right)$ and $\mathrm{TiC}_{x}$ films returned values one order of magnitude higher. Notably, the presence of silicides in MAX phases is known to decrease the conductance. For mixed phases of $\mathrm{Ti}_{3} \mathrm{SiC}_{2}$ with $\mathrm{Ti}_{5} \mathrm{Si}_{4}$ and $\mathrm{Ti}_{5} \mathrm{Si}_{3} \mathrm{C}_{x}$ the resistivity is two times higher $(0.4-0.8 \mu \Omega \cdot \mathrm{m})$ when compared to the single phase. Emmerlich et al. [11] produced $\mathrm{Ti}_{3} \mathrm{SiC}_{2} / \mathrm{TiC}_{x}$ thin films deposited via DC magnetron sputtering from three elemental targets of $\mathrm{Ti}, \mathrm{Si}$, and $\mathrm{C}$ on $\mathrm{MgO}$ and $\mathrm{Al}_{2} \mathrm{O}_{3}$ with an electrical resistivity of $25 \mu \Omega \cdot \mathrm{m}$. However, the electrical resistivity of a good conductor is well known to be in the order of $10^{-8} \Omega \cdot \mathrm{m}$. This value can be influenced by several factors, such as temperature, impurities, and plastic deformation [41]. As discussed above, the defects on the screen-printed films, such as cracks, porosity, and high roughness may disrupt phase continuity decreasing electrical conductivity. Despite the non optimal results the strategy proposed

Table 3 Electrical conductivity at 25 and $400{ }^{\circ} \mathrm{C}$ of layers formed from pastes P2.1 and P2.2 after $5 \mathrm{~h}$ sintering at $1400{ }^{\circ} \mathrm{C}$

\begin{tabular}{ccc}
\hline \multirow{2}{*}{ Sample } & \multicolumn{2}{c}{ Electrical conductivity $\left(\mathrm{S} \cdot \mathrm{m}^{-1}\right)$} \\
\cline { 2 - 3 } & $25{ }^{\circ} \mathrm{C}$ & $400{ }^{\circ} \mathrm{C}$ \\
\hline \multirow{2}{*}{$\mathrm{P} 2.1$} & $9.99 \times 10^{4}$ & $4.63 \times 10^{4}$ \\
& $\left( \pm 6.90 \times 10^{3}\right)$ & $\left( \pm 9.45 \times 10^{3}\right)$ \\
$\mathrm{P} 2.2$ & $2.57 \times 10^{5}$ & $7.13 \times 10^{4}$ \\
& $\left( \pm 1.85 \times 10^{4}\right)$ & $\left( \pm 9.25 \times 10^{4}\right)$ \\
\hline
\end{tabular}


here using elemental powders as the starting materials can be potentially applied for the synthesis of other electrically conductive and oxidation resistant MAX phases, including $\mathrm{Ti}_{3} \mathrm{AlC}_{2}$ and $\mathrm{Ti}_{2} \mathrm{AlC}$ [42].

\section{Conclusions}

Pastes composed of $\mathrm{Ti}, \mathrm{TiC}, \mathrm{Si}$, and $\mathrm{C}$ elementary powders for in situ synthesis of $\mathrm{Ti}_{3} \mathrm{SiC}_{2}$ via screen printing were developed. Pastes containing two powder mixtures $(\mathrm{Ti} / \mathrm{Si} / \mathrm{C}$ and $\mathrm{Ti} / \mathrm{TiC} / \mathrm{Si} / \mathrm{C})$ as reactant powders were produced and observed that the EC content had the greatest influence on the viscosity and all green screen printed films presented a good printing quality. After sintering the screen printed films for 1,3 , and $5 \mathrm{~h}$ at $1400{ }^{\circ} \mathrm{C}$ in argon, $\mathrm{Ti}_{3} \mathrm{SiC}_{2}$ was obtained as the majority phase. Pastes with $\mathrm{Ti} / \mathrm{TiC} / \mathrm{Si} / \mathrm{C}$ in their initial composition exhibited lower roughness, denser microstructure, and higher adhesion in comparison to pastes without $\mathrm{TiC}$ content in their composition. Pastes containing $\mathrm{Ti} / \mathrm{TiC} / \mathrm{Si} / \mathrm{C}$ and excess $\mathrm{Si}$ in their initial composition exhibited $\mathrm{Ti}_{3} \mathrm{SiC}_{2}$ as the main phase. $\mathrm{Ti}_{3} \mathrm{SiC}_{2}$-based films in situ synthesized via screen printing exhibited electrical conductivity ranging from $4.63 \times 10^{4}$ to $2.57 \times 10^{5} \mathrm{~S} \cdot \mathrm{m}^{-1}$.

\section{Acknowledgements}

The authors thank the Central Laboratory of Electronic Microscopy (LCME-UFSC) and the multiuser facility LDRX at UFSC. This study was financed in part by the Coordenação de Aperfeiçoamento de Pessoal de Nível Superior - Brazil (CAPES) - Finance Code 001, under Project number $88881.310728 / 2018-01$ and by the National Council for Scientific and Technological Development (CNPq-Brazil), Project number PVE-CNPq-407102/2013-2.

\section{References}

[1] Barsoum MW, El-Raghy T. Synthesis and characterization of a remarkable ceramic: $\mathrm{Ti}_{3} \mathrm{SiC}_{2}$. J Am Ceram Soc 1996, 79: 1953-1956.

[2] El-Raghy T, Barsoum MW. Diffusion kinetics of the carburization and silicidation of $\mathrm{Ti}_{3} \mathrm{SiC}_{2}$. J Appl Phys 1998, 83: $112-119$.

[3] El-Raghy T, Barsoum MW. Processing and mechanical properties of $\mathrm{Ti}_{3} \mathrm{SiC}_{2}$ : I, reaction path and microstructure evolution. J Am Ceram Soc 1999, 82: 2849-2854.
[4] Emmerlich J, Music D, Eklund P, et al. Thermal stability of $\mathrm{Ti}_{3} \mathrm{SiC}_{2}$ thin films. Acta Mater 2007, 55: 1479-1488.

[5] Sun ZM, Zhou YC. Fluctuation synthesis and characterization of $\mathrm{Ti}_{3} \mathrm{SiC}_{2}$ powders. Mater Res Innov 1999, 2: 227-231.

[6] Zhou Y, Sun Z. Temperature fluctuation/hot pressing synthesis of $\mathrm{Ti}_{3} \mathrm{SiC}_{2}$. J Mater Sci 2000, 35: 4343-4346.

[7] Gao NF, Miyamoto Y, Zhang D. Dense $\mathrm{Ti}_{3} \mathrm{SiC}_{2}$ prepared by reactive HIP. J Mater Sci 1999, 34: 4385-4392.

[8] Gao N, Li J, Zhang D, et al. Rapid synthesis of dense $\mathrm{Ti}_{3} \mathrm{SiC}_{2}$ by spark plasma sintering. J Eur Ceram Soc 2002, 22: 2365-2370.

[9] Carrijo MMM, Caro LG, Lorenz H, et al. $\mathrm{Ti}_{3} \mathrm{SiC}_{2}$-based inks for direct ink-jet printing technology. Ceram Int 2017, 43: 820-824.

[10] Schultheiß J, Dermeik B, Filbert-Demut I, et al. Processing and characterization of paper-derived $\mathrm{Ti}_{3} \mathrm{SiC}_{2}$ based ceramic. Ceram Int 2015, 41: 12595-12603.

[11] Emmerlich J, Högberg H, Sasvári S, et al. Growth of $\mathrm{Ti}_{3} \mathrm{SiC}_{2}$ thin films by elemental target magnetron sputtering. $J$ Appl Phys 2004, 96: 4817-4826.

[12] Carrijo MMM, Lorenz H, Filbert-Demut I, et al. Fabrication of $\mathrm{Ti}_{3} \mathrm{SiC}_{2}$-based composites via threedimensional printing: Influence of processing on the final properties. Ceram Int 2016, 42: 9557-9564.

[13] Li SB, Zhai HX. Synthesis and reaction mechanism of $\mathrm{Ti}_{3} \mathrm{SiC}_{2}$ by mechanical alloying of elemental $\mathrm{Ti}, \mathrm{Si}$, and $\mathrm{C}$ powders. J Am Ceram Soc 2005, 88: 2092-2098.

[14] Dcosta D, Sun W, Lin F, et al. Freeform fabrication of $\mathrm{Ti}_{3} \mathrm{SiC}_{2}$ powder-based structures. J Mater Process Technol 2002, 127: 352-360.

[15] Faddoul R, Reverdy-Bruas N, Blayo A. Formulation and screen printing of water based conductive flake silver pastes onto green ceramic tapes for electronic applications. Mat Sci Eng B 2012, 177: 1053-1066.

[16] Phair JW, Lundberg M, Kaiser A. Leveling and thixotropic characteristics of concentrated zirconia inks for screen printing. Rheol Acta 2009, 48: 121-133.

[17] Lin HW, Chang CP, Hwu WH, et al. The rheological behaviors of screen-printing pastes. $J$ Mater Process Technol 2008, 197: 284-291.

[18] Goldberg HD, Brown RB, Liu DP, et al. Screen printing: A technology for the batch fabrication of integrated chemicalsensor arrays. Sensor Actuat B: Chem 1994, 21: 171-183.

[19] Phair JW. Rheological analysis of concentrated zirconia pastes with ethyl cellulose for screen printing SOFC electrolyte films. J Am Ceram Soc 2008, 91: 2130-2137.

[20] Carrijo MMM, Lorenz H, Rambo CR, et al. Fabrication of $\mathrm{Ti}_{3} \mathrm{SiC}_{2}$-based pastes for screen printing on paper-derived $\mathrm{Al}_{2} \mathrm{O}_{3}$ substrates. Ceram Int 2018, 44: 8116-8124.

[21] Zan QF, Wang CA, Huang Y, et al. The interface-layer and interface in the $\mathrm{Al}_{2} \mathrm{O}_{3} / \mathrm{Ti}_{3} \mathrm{SiC}_{2}$ multilayer composites prepared by in situ synthesis. Mater Lett 2003, 57: 38263832.

[22] Kluthe C, Dermeik B, Kollenberg W, et al. Processing, microstructure and properties of paper-derived porous 
$\mathrm{Al}_{2} \mathrm{O}_{3}$ substrates. J Ceram Sci Technol 2012, 3: 111-118.

[23] Inukai K, Takahashi Y, Ri K, et al. Rheological analysis of ceramic pastes with ethyl cellulose for screen-printing. Ceram Int 2015, 41: 5959-5966.

[24] Méndez-Vilas A, Díaz J. Modern Research and Educational Topics in Microscopy. Badajoz, Spain: Formatex, 2007.

[25] DIN EN ISO 4287: 2010-07. Geometrical Product Specifications (GPS) - Surface texture: Profile method Terms, definitions and surface texture parameters (ISO $4287: 1997$ + Cor 1:1998 + Cor 2:2005 + Amd 1:2009); German version EN ISO 4287:1998 + AC:2008 + A1:2009. 2010.

[26] Murakami S, Ri K, Itoh T, et al. Effects of ethyl cellulose polymers on rheological properties of $(\mathrm{La}, \mathrm{Sr})(\mathrm{Ti}, \mathrm{Fe}) \mathrm{O}_{3^{-}}$ terpineol pastes for screen printing. Ceram Int 2014, 40: 1661-1666.

[27] Sedlaček M, Podgornik B, Vižintin J. Influence of surface preparation on roughness parameters, friction and wear. Wear 2009, 266: 482-487.

[28] Sato F, Li JF, Watanabe R. Reaction synthesis of $\mathrm{Ti}_{3} \mathrm{SiC}_{2}$ from mixture of elemental powders. Mater Trans, JIM 2000, 41: 605-608.

[29] Racault C, Langlais F, Naslain R. Solid-state synthesis and characterization of the ternary phase $\mathrm{Ti}_{3} \mathrm{SiC}_{2}$. J Mater Sci 1994, 29: 3384-3392.

[30] Arunajatesan S, Carim AH. Synthesis of titanium silicon carbide. J Am Ceram Soc 1995, 78: 667-672.

[31] Gauthier V, Cochepin B, Dubois S, et al. Self-propagating high-temperature synthesis of $\mathrm{Ti}_{3} \mathrm{SiC}_{2}$ : Study of the reaction mechanisms by time-resolved X-ray diffraction and infrared thermography. J Am Ceram Soc 2006, 89: 2899-2907.

[32] Wu JY, Zhou YC, Wang JY, et al. Interfacial reaction between $\mathrm{Cu}$ and $\mathrm{Ti}_{2} \mathrm{SnC}$ during processing of $\mathrm{Cu}-\mathrm{Ti}_{2} \mathrm{SnC}$ composite. Zeitschrift Für Met 2005, 96: 1314-1320.

[33] Yang SL, Sun ZM, Hashimoto H. Reaction in $\mathrm{Ti}_{3} \mathrm{SiC}_{2}$ powder synthesis from a Ti-Si-TiC powder mixture. $J$ Alloys Compd 2004, 368: 312-317.

[34] Klemm H, Tanihata K, Miyamoto Y. Gas pressure combustion sintering and hot isostatic pressing in the Ti-Si-C system. $J$
Mater Sci 1993, 28: 1557-1562.

[35] Zhang HB, Zhou YC, Bao YW, et al. Intermediate phases in synthesis of $\mathrm{Ti}_{3} \mathrm{SiC}_{2}$ and $\mathrm{Ti}_{3} \mathrm{Si}(\mathrm{Al}) \mathrm{C}_{2}$ solid solutions from elemental powders. J Eur Ceram Soc 2006, 26: 2373-2380.

[36] Park CS, Zheng F, Salamone S, et al. Processing of composites in the Ti-Si-C system. J Mater Sci 2001, 36: 3313-3322.

[37] Lorenz H, Thäter J, Matias Carrijo MM, et al. In situ synthesis of paper-derived $\mathrm{Ti}_{3} \mathrm{SiC}_{2}$. J Mater Res 2017, 32: 3409-3414.

[38] Radhakrishnan R, Williams J, Akinc M. Synthesis and high-temperature stability of $\mathrm{Ti}_{3} \mathrm{SiC}_{2}$. J Alloys Compd 1999 , 285: 85-88.

[39] Yoo HI, Barsoum MW, El-Raghy T. $\mathrm{Ti}_{3} \mathrm{SiC}_{2}$ has negligible thermopower. Nature 2000, 407: 581-582.

[40] Palmquist J-P, Li S, Persson POA, et al. $\mathrm{M}_{n+1} \mathrm{AX}_{n}$ phases in the $\mathrm{Ti}-\mathrm{Si}-\mathrm{C}$ system studied by thin-film synthesis and $a b$ initio calculations. Phys Rev B 2004, 70: 165401.

[41] Gupta KM, Gupta N. Advanced Electrical and Electronics Materials. Hoboken, NJ, USA: John Wiley \& Sons, Inc., 2015.

[42] Wang $\mathrm{XH}$, Zhou YC. Improvement of intermediatetemperature oxidation resistance of $\mathrm{Ti}_{3} \mathrm{AlC}_{2}$ by preoxidation at high temperatures. Mater Res Innov 2003, 7: 205-211.

Open Access This article is licensed under a Creative Commons Attribution 4.0 International License, which permits use, sharing, adaptation, distribution and reproduction in any medium or format, as long as you give appropriate credit to the original author(s) and the source, provide a link to the Creative Commons licence, and indicate if changes were made.

The images or other third party material in this article are included in the article's Creative Commons licence, unless indicated otherwise in a credit line to the material. If material is not included in the article's Creative Commons licence and your intended use is not permitted by statutory regulation or exceeds the permitted use, you will need to obtain permission directly from the copyright holder.

To view a copy of this licence, visit http://creativecommons.org/licenses/by/4.0/. 